\title{
Comparativo do uso da gestão de design entre empresas da Europa e do interior de São Paulo
}

A comparison between European companies and companies from the interior of São Paulo state in the use of design management.

BONI, Claudio R.; Doutorando; FAAC, UNESP - Univ Estadual Paulista, Bauru

claudioboni@hotmail.com

LANDIM, Paula C.; Livre-Docente; FAAC, UNESP - Univ Estadual Paulista, Bauru

paula@faac.unesp.br

RODRIGUES, Osmar V.; professor-Doutor; FAAC, UNESP - Univ Estadual Paulista, Bauru

osmar@faac.unesp.br

\section{Resumo}

Este estudo é um comparativo do uso da gestão de design entre empresas europeias e empresas situadas no interior do Estado de São Paulo. A gestão de design é uma área pouco estudada no Brasil e pouco utilizada na prática empresarial. Com isso, este estudo tem por objetivo trazer a reflexão acerca da administração do design e da visão dos empresários em relação ao design atuando em conjunto com a administração. Empresas em que a gestão de design tem um papel mais bem definido têm crescido de forma mais sustentável e auxiliado no desenvolvimento social da região onde estão inseridas. Para a realização do estudo foram comparados dados do relatório final do Award for Design Management Innovating and Reinforcing Enterprises com um estudo realizado com aproximadamente 30 empresas da região de Araçatuba/SP.

Palavras Chave: gestão de design; São Paulo; Europa; comparativo.

\begin{abstract}
This paper is a comparison between companies from the interior of São Paulo state in Brazil and European companies in the use of design management. There are little researches about design management in Brazil in the academic and market spheres. Thus, this study aims to bring a reflection about the way that industries are managing design at their routine and how they see the relation between design and administration. The companies in which design management has an important role have been growing sustainable and cooperating for the social development of their region. This article has taken information from the Award for Design Management Innovating and Reinforcing Enterprises report and compared to a research realized with 30 companies from interior of São Paulo state.
\end{abstract}

Keywords: design management; São Paulo; Europe; comparison. 


\section{Introdução}

A gestão de design ainda é uma área pouco investigada no Brasil, tanto pelo meio acadêmico quanto pelas empresas. Essa falta de interesse pelo tema tem apresentado aspectos negativos: o designer não consegue dialogar com a gestão da empresa e o empresário não consegue entender o verdadeiro papel do design. O empresário tende a subutilizar o trabalho especializado dos designers, ou pior, não fazer uso algum, pois não sabe como relacioná-lo às suas atividades empresariais. Outra situação é o fato de os próprios designers desconhecerem conceitos de gestão, fortalecendo, ainda mais, o distanciamento de suas atividades (na maioria dos casos apenas projetuais) com a esfera administrativa e estratégica das empresas.

A relação do design com a gestão empresarial não é algo recente, como aponta Bürdek (2006), relembrando o caso do arquiteto alemão, Peter Behrens, com o trabalho realizado para a Allgemeine Elektricitäts-Gesellschaft (AEG) no início do século XX ou o design corporativo existente na Olivetti desde os anos 30. Outros pesquisadores acreditam que o processo de gestão de design iniciou-se na década de 1960, na Grã-Bretanha, e correspondia ao modo como as agências de design e seus clientes eram gerenciados (MOZOTA, 2011; MARTINS; MERINO, 2011; PRETO; MARTINS, 2013). Entretanto, foi a partir dos anos 80 que a gestão de design ganhou notoriedade e aprofundamento, pois, antes dessa década, o tema não havia sido realmente discutido (VALTONEN, 2007).

Nessa época, como relata Bürdek (2006), os administradores começaram a ver o design de forma diferente, entendendo-o como uma oportunidade de avanço econômico, diferentemente da tratativa, até então, de algo cosmético ou superficial. Esse foi um grande avanço para toda a área do design, pois se iniciou o processo de interação multidisciplinar, isto é, o design se uniu a outras áreas para o desenvolvimento de soluções. Em outras palavras: o design já mantém uma relação com os processos gerenciais das empresas há algumas décadas, o que reforça a ideia de que o Brasil ainda precisa evoluir muito nesta questão. $O$ design é uma área estratégica para os negócios e deve ser visto como tal, tanto pelos empresários quanto pelos designers.

Este estudo tem como objetivo refletir sobre o modo como algumas empresas brasileiras utilizam a gestão de design (mesmo sem saber o que é), comparando-as com empresas europeias, que já recebem apoio de programas de incentivo ao uso do design, atrelando-o à gestão empresarial. Para isso, foram confrontados dois estudos, um realizado na Europa, em 2009, e outro realizado no Brasil em 2015. Cenários tão diferentes e perfis empresariais diferentes devem trazer à tona reflexões acerca das estratégias tomadas pelas indústrias brasileiras em relação ao uso do design e o seu papel no desenvolvimento social, tecnológico e econômico do país.

\section{Revisão de literatura}

O uso da gestão de design pode ser aderido tanto por uma empresa de pequeno porte, situada no interior do Brasil, quanto por uma grande multinacional europeia. O entendimento acerca do uso do design de forma global em uma empresa vai muito além da troca de informações entre departamentos para garantir o sucesso do desenvolvimento do produto. Há uma necessidade de mudança de cultura, em que o design seja uma vertente percebida e administrada por todos. Neste estudo, são apresentados os níveis da gestão de design, sua conceituação e mais dois estudos: um internacional e um nacional. A importância desse comparativo é tanto acadêmica quanto 
mercadológica, pois o Brasil é um país com condição e conhecimento para tonar o design algo mais bem inserido dentro da gestão empresarial.

\subsection{Gestão de design: conceito}

A gestão de design não deve ser vista como um departamento dentro da empresa, tampouco como uma área isolada. Empresas em que o design é considerado uma ferramenta importante devem integrá-lo desde a tomada de decisões, isto é, a elaboração da estratégia. A gestão de design é uma área que insere o design e o coordena em todos os níveis, promovendo a inter-relação dos atores envolvidos direta e indiretamente no processo de design. O objetivo de se utilizar a gestão de design é fazer com que as informações sejam melhor compartilhadas e que todos adiram à estratégia global, de forma a garantir que o projeto seja mais bem administrado por todas as áreas.

Kootstra (2009) considera que gestão de design está relacionada a certas atividades da própria administração, dos métodos e das habilidades que são necessárias para aperfeiçoar e gerenciar os processos de design de uma empresa. A gestão de design envolve, então, processos em andamento e decisões de negócio, o que possibilita a inovação e criação eficiente de produtos corretamente desenvolvidos, serviços, comunicação, ambientes e marcas que elevam a qualidade de vida e promovem o sucesso organizacional (DESIGN MANAGEMENT INSTITUTE, ?). Os gestores devem enxergar a gestão de design como uma ferramenta para sistematizar e aperfeiçoar o processo de coordenação e articulação dos recursos de sua empresa, quando voltados ao design.

A utilização do design de forma cultural dentro da administração não é uma atitude comum em grande parte das empresas brasileiras, mesmo quando o eixo é a inovação. Os empresários dão muita importância às planilhas e aos controles, procedimentos e formas de qualificar os processos, ações, muitas vezes, técnicas e objetivas, mas que não têm relação com a experiência que o design pode promover (BRUNNER; EMERY, 2010). A gestão de design tem como foco não apenas parametrizar o processo de design, mas também tornar o processo de desenvolvimento e lançamento do produto mais adequado ao sistema da organização. Realizar a gestão de design é agregar a participação de agentes de design em projetos diversos, evitando visões extremamente especializadas e rígidas, que podem evitar mudança e evolução de produtos e serviços (MOZOTA, 2011).

De acordo com o Design Management Institute (?), em um nível mais profundo, a gestão de design busca relacionar design, inovação, tecnologia, gestão e as pessoas para promover vantagens competitivas através dos fatores econômicos, socioculturais e ambientais. A gestão de design abrange a multidisciplinaridade [e muitas vezes a interdisciplinaridade] de áreas como o próprio design, a gestão, o marketing e outras, juntamente com a administração de recursos humanos, como clientes, designers, stakeholders, etc. (BEST, 2012). Por fim, é importante que se entendam os níveis da gestão de design em uma empresa. Mozota (2011) considera que existem o nível operacional, nível tático e nível estratégico.

Quadro 1 - Caixa de ferramentas do gerente de design.

\begin{tabular}{lll}
\hline Design operacional & Design funcional & Design estratégico \\
\hline Estratégia & Estratégia & Estratégia
\end{tabular}


Definir uma política de design nas estratégias de produtos e de comunicação;

Estabelecer uma política de marca e o papel que o design desempenha na marca.

\section{Planejamento}

Esboçar briefings de design

\section{Estrutura}

Selecionar designers;

Indicar equipes e pessoas que ficarão conectadas com os designers; Nomear um "líder de design".

\section{Finanças}

Gerenciar os orçamentos de projetos de design;

Estimar custos do design.

\section{Recursos Humanos}

Definir as competências do design.

\section{Informações}

Desenvolver a compreensão de metas da empresa entre os designers;

Esboçar documentação e o controle de projetos.

\section{Comunicação}

Formar relações com escolas de design;

Criar orientações gráficas para a comunicação.

\section{P\&D}

Apoiar transferências de tecnologia
Coordenar a estratégia de design como os departamentos de marketing, inovação e

comunicação;

Difundir uma estratégia de design na implementação da estratégia empresarial.

\section{Planejamento}

Especificar

procedimentos/cronogramas;

Definir padrões de desempenho de design;

Determinar relacionamentos entre design e qualidade total.

\section{Estrutura}

Expor o papel, o local de trabalho e as tarefas do gerente de design na estrutura da empresa;

Criar um modelo-matriz para inovação e projetos;

Implementar um serviço interno de design.

\section{Finanças}

Listar fornecedores e designers colaboradores;

Garantir que o orçamento seja programado.

\section{Recursos Humanos}

Promover a compreensão do design entre os participantes da empresa

\section{Informações}

Esboçar planos de marketing, design e produção;

Disseminar o know-how do design na empresa.

\section{Comunicação}

Administrar o relacionamento entre padrões gráficos e arquitetônicos.

\section{P\&D}

Administrar as relações com os fornecedores;

Formar uma política de qualidade.
Indicar uma estratégia empresarial que incorpore metas do design;

Garantir que a estratégia de design reagrupe produtos, comunicação, espaço e informações.

\section{Planejamento}

Programar projetos de design;

Lançar testes de design;

Determinar padrões de design: normas gráficas, estruturais e de produtos.

\section{Estrutura}

Representar o design no nível da alta administração;

Criar uma mentalidade que seja favorável ao design.

\section{Finanças}

Estabelecer as regulamentações de gestão de design;

Assegurar que haja um orçamento para implementar a estratégia do design.

\section{Recursos Humanos}

Criar um clima favorável ao design; Influenciar as contratações e o gerenciamento das carreiras em design.

\section{Informações}

Comunicar a missão do design na empresa;

Implementar a detecção de tendências.

\section{Comunicação}

Promover concursos de design; Comunicar conceitos de produto.

P\&D

Criar um relacionamento entre design e detecção de tendências tecnológicas. 
Fonte: Mozota (2011)

\subsection{A incorporação da gestão de design na prática diária dos negócios: Uma análise das práticas de gestão de design na Europa}

A criação de um prêmio para empresas que utilizam a gestão de design é o propósito do Award for Design Management Innovating and Reinforcing Enterprises (ADMIRE). Além disso, devese considerar o aprofundamento do conhecimento a respeito dos benefícios da gestão de design como um grande resultado deste projeto, especialmente para as micro e pequenas empresas. $\mathrm{O}$ programa foi parcialmente financiado pela European Commission Directorate General Enterprises and Industry, como parte do programa PRO INNO Europe, que teve foco em pesquisa, em inovação e no desenvolvimento de políticas de inovação. Além dos pesquisadores ligados ao Design Management Europe (DME), também fizeram parte do estudo pesquisadores de diversas universidades europeias. O número de empresas participantes foi 605 , que estavam espalhadas por diversos países da Europa e dividiam-se entre empresas de manufatura e não manufatureiras.

Participaram do projeto 19 parceiros e 10 agentes de 12 países, componentes do DME, que teve duração de dois anos. O estudo, descrito por Kootstra (2009), traz todas as informações acerca do levantamento conduzido pelos pesquisadores do DME e outras informações sobre a gestão de design. Para este comparativo, no entanto, serão abordadas apenas as informações relacionadas aos resultados da pesquisa, realizada entre final de 2008 e começo de 2009, com empresas de todos os tamanhos, sobre o processo de design.

\subsubsection{Resultados}

As empresas foram questionadas em relação a alguns fatores estratégicos do processo de design e como eles ocorriam. Nota-se claramente que há um cenário positivo (gráfico 1), pois na demarcação à direta, com coloração mais clara, estão dispostos os resultados mais positivos, que apresentam o índice de empresas que consideram a ação descrita na questão como sendo um procedimento padrão. Grande parte das empresas entrevistadas tem seus objetivos de design bem definidos, e há uma estratégia definida para o design, assim como a existência de um gestor do projeto desde o início do processo. Além disso, o papel e as responsabilidades dos designers são bem destacados, indiferentemente de eles serem internos ou externos, como relata a maior parte dos entrevistados. 


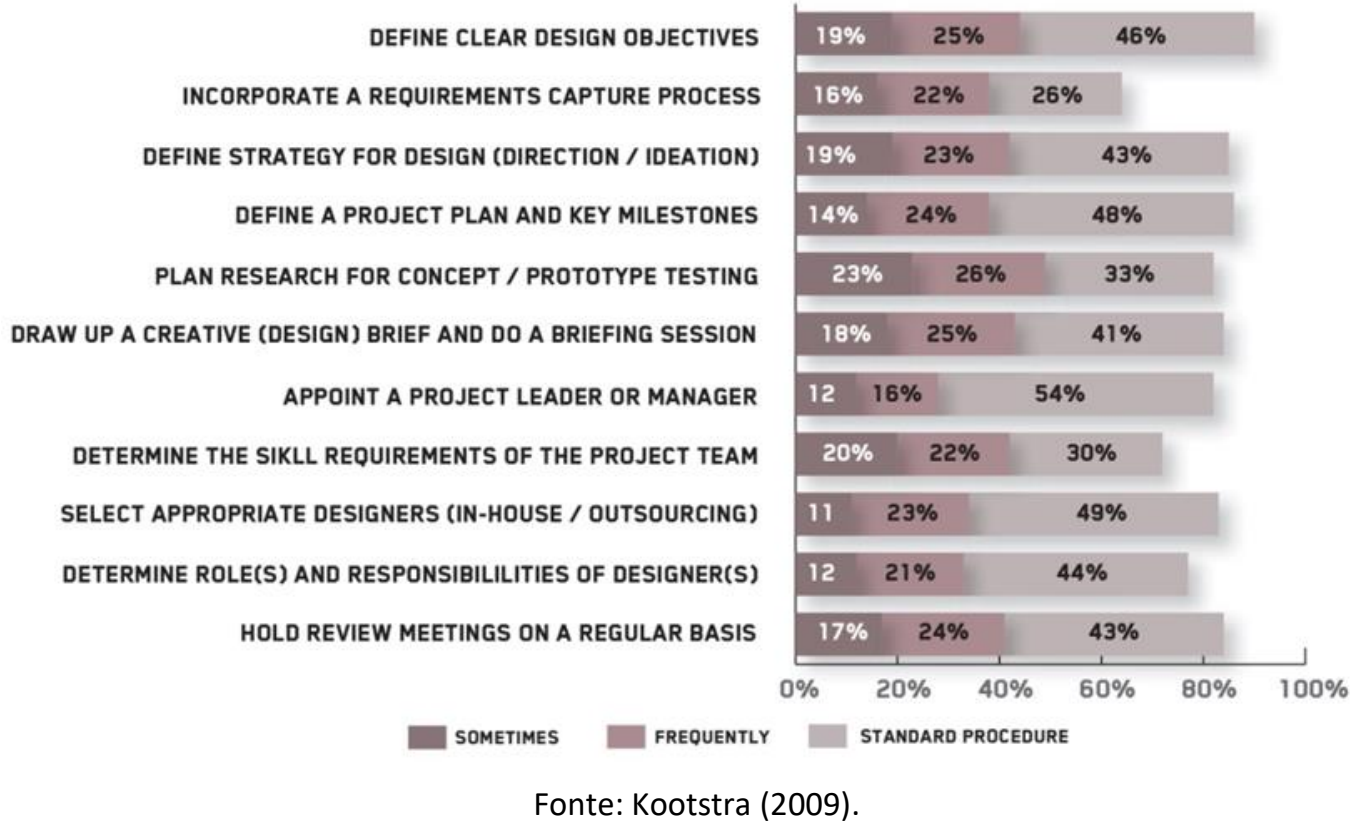

Já o gráfico 2 corresponde às pesquisas de necessidades dos consumidores, apresentando tópicos relacionados aos métodos comumente utilizados pelas empresas. $O$ design é incrivelmente visto como uma ferramenta estratégica para inovação baseada no usuário. Importantes autores têm apontado que as empresas precisam entrar em sintonia com as aspirações e desejos dos usuários e devem entender suas necessidades para que possam chegar a inovações bem-sucedidas. É possível ver no gráfico que algumas técnicas são comumente utilizadas pelas empresas, como obter informações através do conhecimento de engenheiros e marqueteiros, apresentado no primeiro tópico. A soma das respostas das empresas que utilizam essa técnica frequentemente com as que utilizam isso como um procedimento padrão resulta em um índice de $61 \%$. Há, também, os dois últimos tópicos, que apresentam um resultado expressivo. O penúltimo refere-se à ativa participação dos usuários no processo de desenvolvimento e tem $47 \%$ de respostas muito positivas (frequentemente e procedimento padrão). O último resultado também é muito satisfatório, pois $61 \%$ das empresas declaram que utilizam feedback dos usuários para desenvolver e testar produtos ou melhorar serviços.

Gráfico 2 - Utilização de informações dos consumidores. 


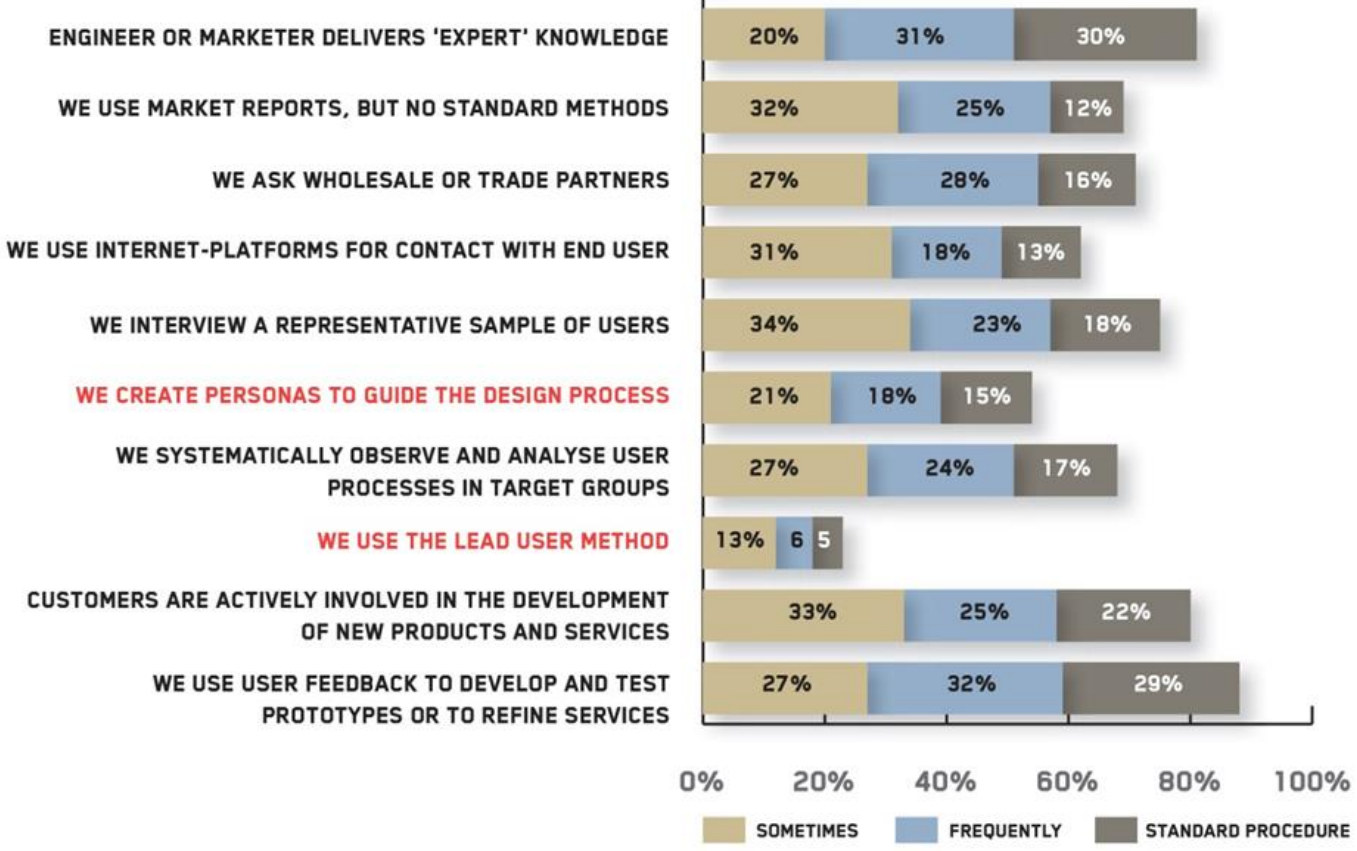

Fonte: Kootstra (2009).

Outra questão muito interessante da pesquisa foi direcionada ao nível de coordenação do design. Foram dispostos alguns tópicos para facilitar a identificação do respondente. Como mostra o gráfico 3, a maioria das empresas, seja de serviços ou indústria, tem um departamento de design interno, o que não significa que não há terceirizações em algumas partes do processo. Mesmo em um continente onde a gestão de design é tão desenvolvida, nota-se que há pouca adesão de profissionais dessa área, tanto internamente quanto externamente. Apenas $12 \%$ das indústrias têm um especialista na área e outras $15 \%$ contratam algum consultor externo.

Gráfico 3 - Capacidade das empresas de concentração de esforços em design. 


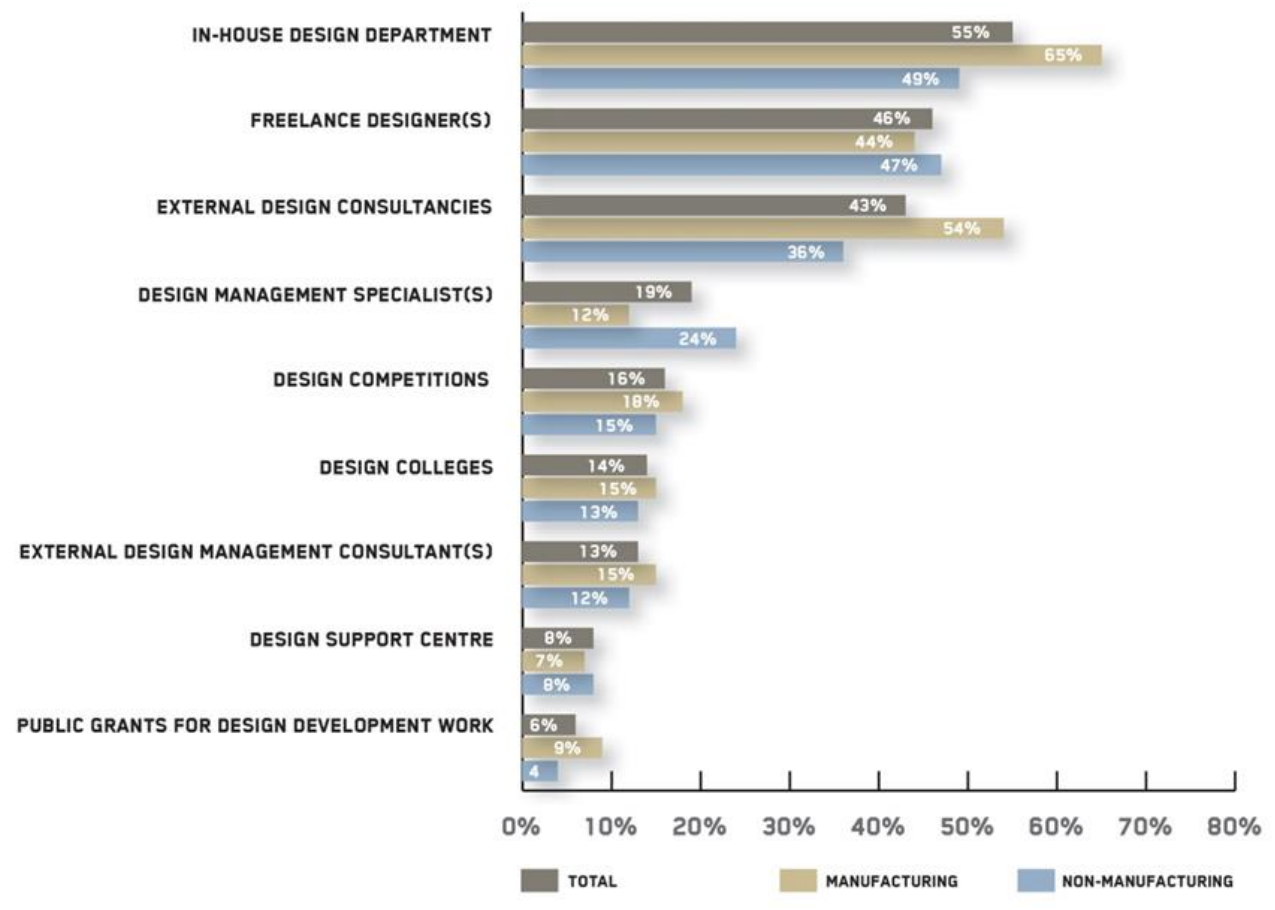

Fonte: Kootstra (2009).

Aos entrevistados, também foi apresentada uma lista de ferramentas e métodos para o processo de desenvolvimento e gestão do design. De forma surpreendente, o resultado revela que grande parte dos respondentes não estava familiarizada com os tópicos apresentados (gráfico 4), pois a opção "Não aplicável/Não conheço" foi intensamente escolhida (aparece de forma oculta no gráfico, contrária às respostas obtidas). A Europa tem uma cultura de design muito desenvolvida e nos surpreende, mesmo para empresas pequenas, pelos resultados tão baixos, como os tópicos "Auditoria do Processo de Design" e "Gestão do Ciclo de Vida" (do produto ou serviço). A "Análise de custo" e a "Análise de portfólio" foram tópicos mais bem observados, junto com "Políticas de design" e "Manual/Diretrizes de design", mostrando, talvez, que as empresas estão preparadas internamente e, possivelmente, o futuro seja investir em auditorias.

Gráfico 4 - Ferramentas e Métodos utilizados. 


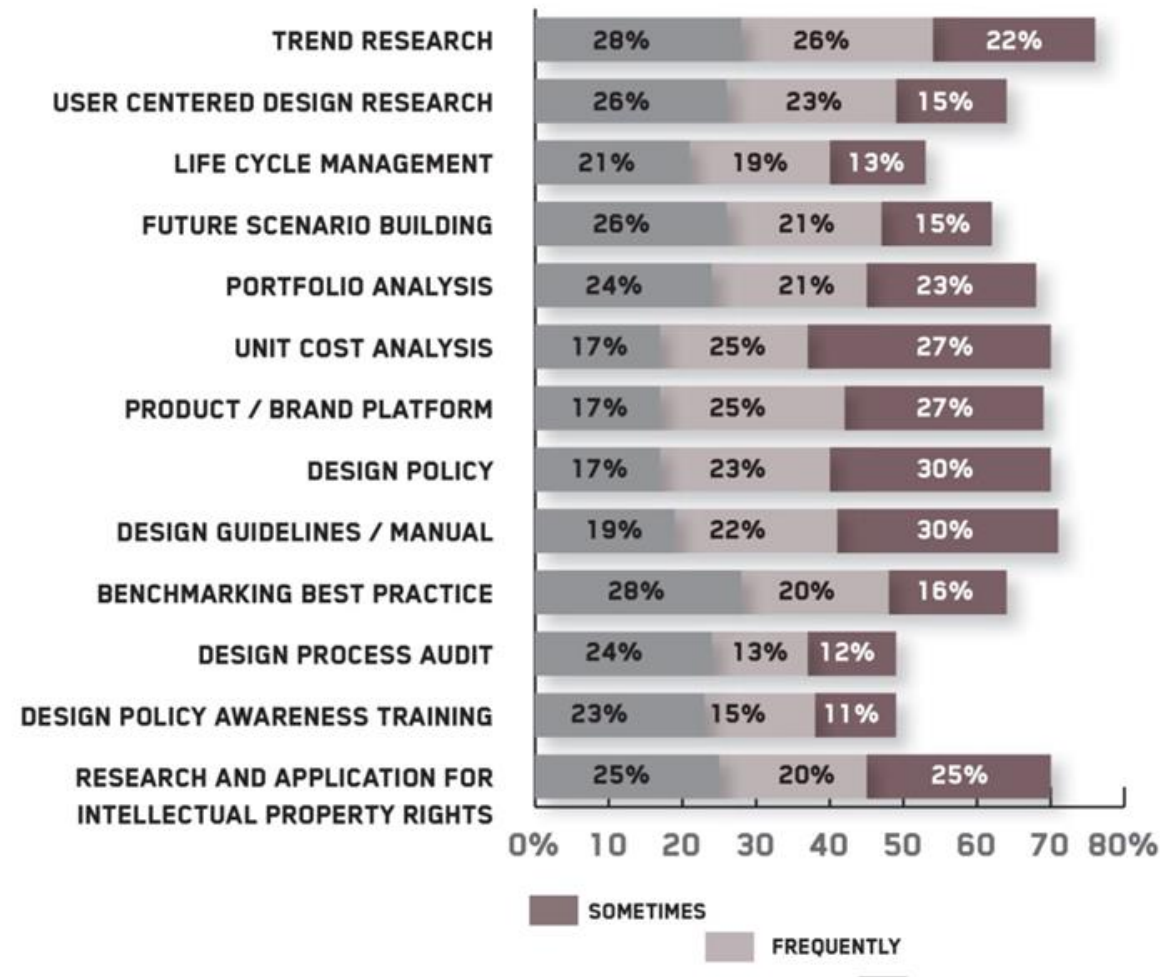

Fonte: Kootstra (2009).

A maior parte dos resultados da pesquisa é positiva e denota o design como uma estratégia empresarial para essas organizações. É importante lembrar, que a pesquisa foi realizada em 2009 e que, possivelmente, essas empresas evoluíram após o término do projeto, fazendo com que a gestão de design esteja mais presente em suas atividades atuais. O entendimento geral, que se deve tirar deste estudo, é o alinhamento da gestão de negócios à gestão de design, que, mesmo aparentando um cenário negativo em alguns momentos (gráfico 3), é fortemente empregado ao se entender a pesquisa de forma global. A empresas utilizam ferramentas de gestão de design, sem mesmo conhecê-las, pois sinalizam uma interface entre as questões estratégicas e operacionais do projeto.

\subsection{Diagnóstico setorial da gestão de design no interior do Estado de São Paulo}

Uma pesquisa, realizada pelos mesmos autores deste artigo (BONI, 2015), baseou-se na coleta de dados acerca da gestão de design com indústrias de transformação das microrregiões de Birigui e Araçatuba/SP. A pesquisa foi submetida ao Comitê de Ética (CEP) da Faculdade de Odontologia (FOA) da Universidade Estadual Paulista "Júlio de Mesquita Filho", campus de Araçatuba, e foi aplicado um Termo de Consentimento Livre e Esclarecido (TCLE), que atendeu à Resolução 466/12 -CNS-MS. Foi utilizado um formulário baseado no questionário desenvolvido pelo DME Award (tópico 2.2) e aplicado a gestores e empresários de diversos ramos (menos o calçadista, predominante na região). De acordo com os pesquisadores, diversas questões provindas do questionário do DME foram rejeitadas em função de serem voltadas a empresas situadas em locais em que o design não faz parte da cultura empresarial. Outras, no entanto, foram adaptadas à 
realidade do mercado brasileiro, mais precisamente às microrregiões de Araçatuba e Birigui. A intenção do pesquisador com essas alterações foi tornar o formulário mais funcional e, consequentemente, a pesquisa mais precisa. Na sequência, são apresentados alguns resultados que foram extraídos da pesquisa realizada no Brasil, mais precisamente os dados que podem ser comparados ao estudo internacional, apresentado anteriormente.

\subsubsection{Resultados}

O desenvolvimento de um projeto sem os objetivos claros é um risco, e para uma parte dos entrevistados, principalmente para $25 \%$ deles, isto é uma realidade. Isso sinaliza que muitos projetos se iniciam sem um objetivo, promovendo a ideia de que não se sabe aonde se quer chegar. Isso é reforçado no segundo tópico, que mostra o índice de $65 \%$ (somatória dos dois últimos resultados) de empresas que não têm estratégia de design. É importante destacar que empresas do segmento moveleiro, expositores de mercado, móveis hospitalares, refrigeração e balcões de ambientes comerciais e muitos outros participaram da pesquisa. Empresas deste tipo devem, fundamentalmente, estar alinhadas às práticas de design, pois são áreas que desenvolvem produtos de uso direto por pessoas. Falta de briefing de projeto, falta de cronograma e de definição de investimentos e falta de diretrizes para o desenvolvimento dos produtos e da comunicação foram itens com resultados muito negativos para estes tipos de segmentos.

Quadro 2 - Indique quais processos de design ocorrem na empresa.

\begin{tabular}{|c|c|c|c|c|c|}
\hline Ação & $\begin{array}{l}\text { Concordo } \\
\text { totalmente }\end{array}$ & $\begin{array}{l}\text { Concordo } \\
\text { em partes }\end{array}$ & Concordo & $\begin{array}{l}\text { Discordo } \\
\text { em partes }\end{array}$ & $\begin{array}{l}\text { Discordo } \\
\text { totalmente }\end{array}$ \\
\hline Objetivos claramente definidos & $39 \%$ & $25 \%$ & $7 \%$ & $7 \%$ & $18 \%$ \\
\hline Há uma estratégia de design & $11 \%$ & $4 \%$ & $7 \%$ & $14 \%$ & $51 \%$ \\
\hline $\begin{array}{l}\text { É formulado um projeto } \\
\text { (cronograma, investimento, } \\
\text { recursos, etc) }\end{array}$ & $32 \%$ & $4 \%$ & $11 \%$ & $4 \%$ & $46 \%$ \\
\hline É elaborado um Briefing & $29 \%$ & $18 \%$ & $7 \%$ & $4 \%$ & $39 \%$ \\
\hline Geração e protótipos de ideias & $93 \%$ & $0 \%$ & $0 \%$ & $0 \%$ & $4 \%$ \\
\hline $\begin{array}{l}\text { É apontado um gestor para o } \\
\text { projeto }\end{array}$ & $36 \%$ & $11 \%$ & $29 \%$ & $4 \%$ & $18 \%$ \\
\hline $\begin{array}{l}\text { São selecionados os } \\
\text { profissionais envolvidos } \\
\text { (internos e externos) }\end{array}$ & $39 \%$ & $14 \%$ & $18 \%$ & $7 \%$ & $18 \%$ \\
\hline $\begin{array}{l}\text { São determinadas as regras e } \\
\text { diretrizes para a execução do } \\
\text { projeto }\end{array}$ & $18 \%$ & $14 \%$ & $11 \%$ & $0 \%$ & $54 \%$ \\
\hline $\begin{array}{l}\text { São feitas reuniões regulares } \\
\text { durante o projeto }\end{array}$ & $25 \%$ & $25 \%$ & $18 \%$ & $0 \%$ & $29 \%$ \\
\hline
\end{tabular}


O quadro 3 reflete o modo como as empresas realizam a pesquisa de design, que, normalmente, é feita para dar início ao processo de desenvolvimento dos produtos. Há um grande volume de dados que pode ser confrontado para que se gerem diversas possibilidades de análise. Entretanto, deve-se atentar às informações mais relevantes, indiferentemente de serem positivas ou negativas. Há destaque ao fato de as revendas e os representantes serem, tradicionalmente, os grandes fornecedores de informações e, desfavoravelmente, a maioria dos entrevistados não envolverem os clientes no processo. Não se deve considerar a opinião das revendas como algo negativo, contudo é importante que os clientes sejam mais bem observados durante o processo de design, pois a não aceitação do produto impacta diretamente o volume de vendas.

O uso de métodos, como o Lead User e a criação de personas, está totalmente fora da rotina de design dessas empresas. Na verdade, esse tipo de prática só foi constatado efetivamente em uma grande empresa de Araçatuba, fabricante de eletrodomésticos. Nessa empresa, há um gerente com formação em design pela Universidade Positivo e pós-graduação na área pela UTFPR, ambas de Curitiba. Isso revela o quão importante é a capacitação profissional para o desenvolvimento de técnicas de design e o melhor aproveitamento delas. Outro detalhe importante é a administração dos recursos de marketing, que, também de forma negativa, se mostraram subutilizados pelas empresas. Pesquisa com os profissionais de marketing e relatórios de mercado são formas de melhor entender as demandas mercadológicas e facilitar a elaboração de uma estratégia integrada com o design. Neste caso, mais da metade dos respondentes assumiram não utilizar tais práticas.

Quadro 3 - Como é feita a pesquisa de design?

\begin{tabular}{|c|c|c|c|c|c|}
\hline Ação & $\begin{array}{l}\text { Concordo } \\
\text { totalmente }\end{array}$ & $\begin{array}{l}\text { Concordo } \\
\text { em partes }\end{array}$ & Concordo & $\begin{array}{l}\text { Discordo } \\
\text { em partes }\end{array}$ & $\begin{array}{l}\text { Discordo } \\
\text { totalmente }\end{array}$ \\
\hline $\begin{array}{l}\text { Um engenheiro ou um } \\
\text { marqueteiro fornece as } \\
\text { informações }\end{array}$ & $18 \%$ & $0 \%$ & $14 \%$ & $0 \%$ & $54 \%$ \\
\hline $\begin{array}{l}\text { Nós utilizamos relatórios de } \\
\text { mercado }\end{array}$ & $14 \%$ & $11 \%$ & $11 \%$ & $0 \%$ & $51 \%$ \\
\hline $\begin{array}{l}\text { Nós perguntamos aos } \\
\text { representantes ou revendas }\end{array}$ & $75 \%$ & $11 \%$ & $7 \%$ & $0 \%$ & $4 \%$ \\
\hline $\begin{array}{l}\text { Nós utilizamos a internet para } \\
\text { atingir os clientes finais }\end{array}$ & $18 \%$ & $11 \%$ & $18 \%$ & $4 \%$ & $46 \%$ \\
\hline $\begin{array}{l}\text { Nós entrevistamos muitos } \\
\text { clientes }\end{array}$ & $21 \%$ & $7 \%$ & $39 \%$ & $14 \%$ & $14 \%$ \\
\hline $\begin{array}{l}\text { Nós criamos "personas" para } \\
\text { guiar o desenvolvimento }\end{array}$ & $4 \%$ & $2 \%$ & $1 \%$ & $0 \%$ & $82 \%$ \\
\hline $\begin{array}{l}\text { Nós observamos e analisamos } \\
\text { sistematicamente alguns } \\
\text { clientes-chave }\end{array}$ & $25 \%$ & $14 \%$ & $25 \%$ & $7 \%$ & $25 \%$ \\
\hline $\begin{array}{l}\text { Nós utilizamos Métodos de } \\
\text { Usuários Líderes (Lead user } \\
\text { methods) }\end{array}$ & $4 \%$ & $0 \%$ & $11 \%$ & $4 \%$ & $79 \%$ \\
\hline
\end{tabular}


Os clientes são envolvidos ativamente no desenvolvimento

Nós utilizamos feed-back do mercado

Um engenheiro ou um marqueteiro fornece as informações
$14 \%$

$4 \%$

$21 \%$

$0 \%$

$18 \%$
$18 \%$

$14 \%$
$0 \%$

$7 \%$

$0 \%$
$68 \%$

$4 \%$

$54 \%$

Fonte: Boni (2015).

Adentrando especificamente a área do design, a pesquisa trouxe, também, uma questão relacionada ao modo como ele é trabalhado na empresa. Nesse caso, há preponderância do uso de um departamento de design interno, com $43 \%$ de respondentes, e, na segunda posição, com $29 \%$, encontra-se a opção "Outros", que corresponde às empresas que têm seu desenvolvimento de produtos, pesquisa e comunicação administrados pelo diretor. É importante lembrar que essa questão possibilitava mais de uma resposta, com isso, algumas empresas tinham seus departamentos de design internos e contavam com apoio de freelancers para determinadas atividades. Um dado importante, que não consta no gráfico, mas que é revelado pelo pesquisador que realizou as entrevistas, é que, ao assumirem a existência de um departamento de design, os empresários afirmaram que, na verdade, existem pessoas de vários setores solicitadas a participarem de etapas específicas, durante o desenvolvimento do produto. Por isso, eles consideram que há um departamento, quando, na verdade, não há.

Gráfico 5 - De que forma sua empresa trabalha com o design?
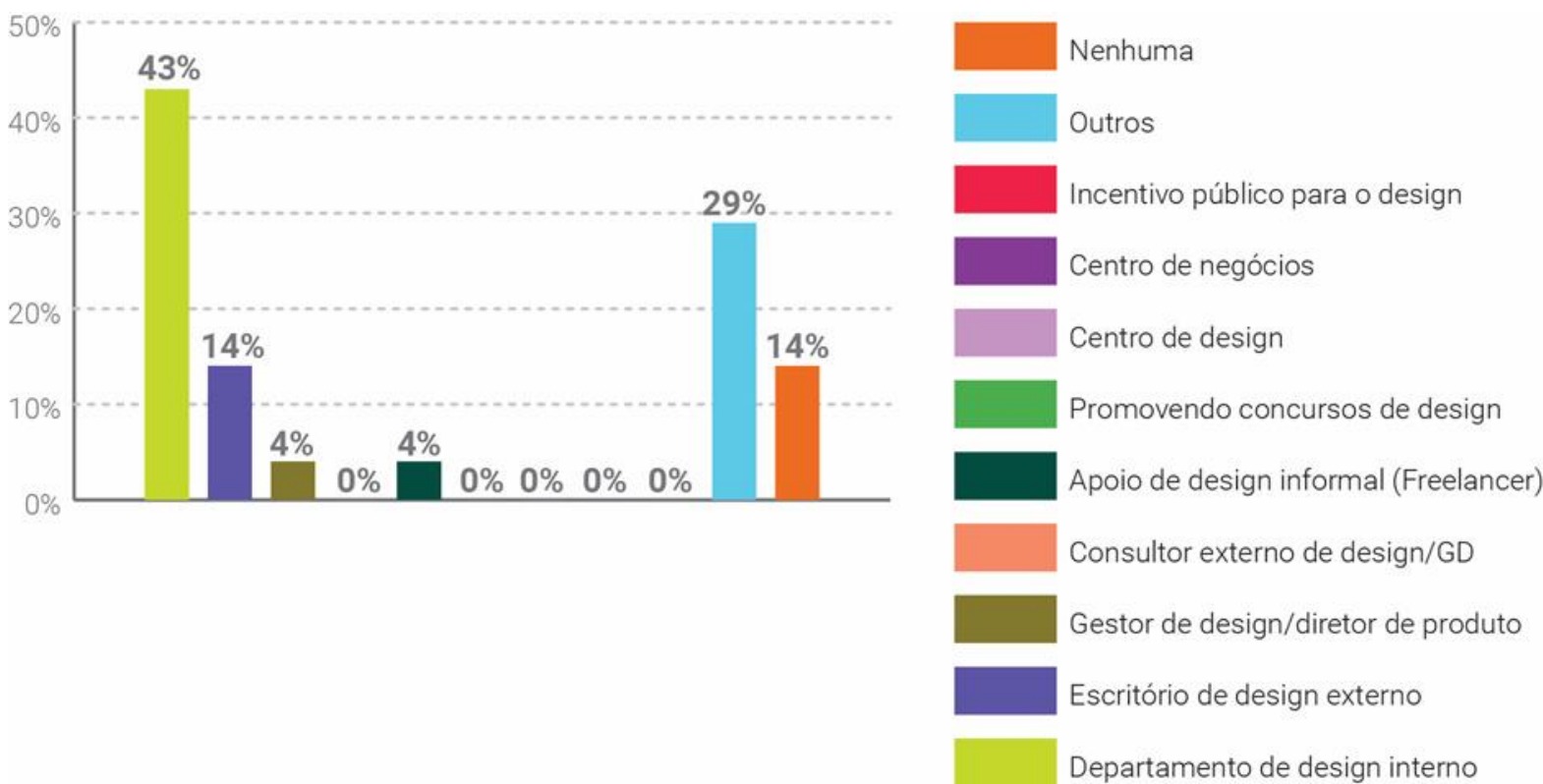

Fonte: Boni (2015).

O quadro 3 disponibiliza dados coletados sobre as ferramentas e métodos, que são empregados pelos participantes durante o projeto. No quadro, é fácil identificar quais atividades de design estão mais presentes nas empresas, como a "Análise de portfólio" e a "Análise de custo", 
com $61 \%$ e $82 \%$ de respondentes respectivamente. Ambas as práticas não são específicas da área de design e são comumente utilizadas por qualquer indústria. Segundo os entrevistados, essas são as primeiras ações tomadas durante o projeto, pois sinalizam a possibilidade de dar andamento ao desenvolvimento ou não. Em outras palavras, como grande parte das empresas tem observado mais a concorrência do que os clientes, há uma preocupação, desde o início, com o preço do produto a ser lançado, que, normalmente, é elaborado de forma estimada. A análise de portfólio, neste caso, entra como forma de reavaliar os próprios projetos e componentes, para que se possa identificar algo já existente, que tenha possibilidade de ser ajustado ou redesenhado de forma a atender à nova demanda. Isso evita altos investimentos e garante o processo produtivo já existente, de acordo com os respondentes.

Um dado alarmante está relacionado ao primeiro item do quadro 4, a "Pesquisa de tendência", pois traz um resultado, de certa forma, negativo para a área de design. Para $43 \%$ das empresas, não há esse tipo de levantamento durante o projeto, pois, em muitos casos, acreditam não haver necessidade. Entretanto, essas empresas são de segmentos em que o design está muito presente, pois são fabricantes de móveis de madeira e de aço, de equipamentos para construção civil (equipamentos e aquecedores solares), de móveis escolares, de escapamentos para motocicletas, de equipamentos para academia e outros. Todos esses segmentos utilizam o design de forma efetiva e como diferencial estratégico em diversas regiões do Brasil e do mundo. Não se espera, no entanto, que práticas como "Pesquisa centrada no usuário" e "Auditoria de design" sejam largamente utilizadas pelas empresas em uma região com tão pouco desenvolvimento do design. Isso fica presente na pesquisa, contudo, as ferramentas FMEA e "Gestão do ciclo de vida do produto" já são utilizadas há muito tempo, no Brasil, por empresas dos mais variados ramos, pois são formas de tornar os projetos mais seguros. Neste caso, a maioria das empresas declara não utilizar essas técnicas e, como fator agravante, grande parte delas assumiu sequer ter conhecimento desses termos.

Quadro 4 - Quais ferramentas e métodos são empregados pela empresa durante o processo de design?

\begin{tabular}{|c|c|c|c|c|c|}
\hline Ação & $\begin{array}{l}\text { Concordo } \\
\text { totalmente }\end{array}$ & $\begin{array}{l}\text { Concordo } \\
\text { em partes }\end{array}$ & Concordo & $\begin{array}{l}\text { Discordo } \\
\text { em partes }\end{array}$ & $\begin{array}{l}\text { Discordo } \\
\text { totalmente }\end{array}$ \\
\hline Pesquisa de tendência & $36 \%$ & $7 \%$ & $11 \%$ & $0 \%$ & $43 \%$ \\
\hline $\begin{array}{l}\text { Pesquisa de design centrado no } \\
\text { usuário }\end{array}$ & $4 \%$ & $11 \%$ & $4 \%$ & $4 \%$ & $75 \%$ \\
\hline $\begin{array}{l}\text { Gestão do ciclo de vida do } \\
\text { produto }\end{array}$ & $4 \%$ & $4 \%$ & $4 \%$ & $11 \%$ & $75 \%$ \\
\hline Análise de portfólio & $61 \%$ & $7 \%$ & $21 \%$ & $4 \%$ & $4 \%$ \\
\hline Análise de custo & $82 \%$ & $0 \%$ & $14 \%$ & $0 \%$ & $0 \%$ \\
\hline Práticas de Benchmarking & $32 \%$ & $0 \%$ & $21 \%$ & $18 \%$ & $25 \%$ \\
\hline Auditoria do processo de design & $4 \%$ & $0 \%$ & $4 \%$ & $4 \%$ & $86 \%$ \\
\hline $\begin{array}{l}\text { Análise de modo e efeitos de } \\
\text { falhas (FMEA) }\end{array}$ & $4 \%$ & $0 \%$ & $7 \%$ & $0 \%$ & $86 \%$ \\
\hline
\end{tabular}


Fonte: Boni (2015).

Nota-se, com o resultado da pesquisa, que mesmo o design operacional (das práticas projetuais) não é bem utilizado pelas indústrias das regiões pesquisadas. Há necessidade de conhecimentos básicos na área e melhor utilização das técnicas de design. Mesmo as empresas, que têm designers em sua equipe têm deixado de praticar atividades de extrema importância para o processo. $O$ que se percebe é que, além de não haver gestão de design, também não há o puro design, a prática projetual mínima. Ao admitirem a não contratação ou o não envolvimento dos designers no processo, as empresas assumem o risco de não desenvolverem soluções mais adequadas ao uso das pessoas. A gestão de design, definitivamente, não faz parte da rotina destas empresas.

\section{Conclusão}

Afirmar seguramente que as indústrias da região de Araçatuba, participantes da pesquisa, não utilizam design é algo indevido e generalista. Contudo, assumir a falta de gestão de design nestas empresas, ou a definir como incipiente é algo muito perceptível diante deste estudo. Mesmo o design operacional se mostra pouco explorado, mal administrado e distante da gestão dessas empresas. Há uma antinomia entre o design e a administração, em que o design acaba por ser o lado mais fraco e menos observado. Pode-se constatar que algumas indústrias da região de Araçatuba não conhecem as ferramentas comuns da área de design, mesmo assumindo trabalharem com essa área em sua rotina.

Já as empresas europeias se mostram mais evoluídas em vários aspectos, principalmente no entendimento do papel do design em seus negócios. O design aparece como um elemento estratégico e diferencial para a sustentabilidade da empresa, principalmente para as indústrias, que empregam comumente consultores de design para auxiliarem em seus projetos. Além disso, como mostra a pesquisa, as empresas são assessoradas por órgãos públicos e privados no uso e entendimento do design, contribuindo para que os produtos e serviços sejam importantes não apenas para os lucros, mas para o benefício econômico e social da região onde as empresas estão inseridas.

As indústrias brasileiras, não somente da região de Araçatuba, têm muito a aprender com as empresas europeias no quesito gestão do design, mas, mais do que isso, essas empresas devem assumir o design como parte importante dos seus negócios. Este estudo não tem o objetivo de tornar as empresas brasileiras iguais às empresas europeias, tampouco indicar-lhes um caminho correto. O que se espera com esse estudo é que a gestão de design seja vista como uma oportunidade para o desenvolvimento local, por meio do uso de ferramentas e métodos adequados à realidade brasileira, de formar a contribuir para a melhora econômica, social e tecnológica do país. Vale lembrar, ainda, que novos estudos devem ser desenvolvidos acerca da gestão de design no Brasil, para que se tenha um panorama global e que sirvam de base para a formação de estratégias públicas e privadas que auxiliem o processo de crescimento sadio dessas empresas. 


\section{Referências}

BEST, Kathryn. Fundamentos de Gestão do Design. Tradução: André de Godoy Vieira. Porto Alegre: Bookman, 2012. 208 p. ISBN 978-85-407-0146-5.

BONI, Claudio R. Diretrizes para o uso da gestão de design a partir de um diagnóstico setorial das microrregiões de Araçatuba e Birigui do Estado de São Paulo. 2015. 157 f. Dissertação (Mestrado em design)-Universidade Estadual Paulista “Júlio de Mesquita Filho", Bauru, 2015.

BRUNNER, Robert; EMERY, Stewart. Gestão Estratégica do Design: Como um Ótimo Design Fará as Pessoas Amarem sua Empresa. São Paulo: M.Books do Brasil, 2010. ISBN: 978-85-7680-084-2.

BÜRDEK, Bernhard E. Design: História, Teoria e Prática do Design de Produtos. Tradução Freddy Van Camp. São Paulo: Edgar Blücher, 2006. 496 p. ISBN 85-212-0375-6.

DESIGN MANAGEMENT INSTITUTE. What is Design Management? Tradução nossa. Disponível em: http://www.dmi.org/?What_is_Design_Manag. Acesso em: 14 de julho de 2014.

KOOTSTRA, Gert L. MBM. The Incorporation of Design Management in Today's Business Practises: An Analises of Design Management Practises in Europe. DME SURVEY. Rotterdam: INHOLLAND University, 2009. Disponível em: <http://www.designmanagementexcellence.com/wpcontent/uploads/2013/05/DME_Survey09.pdf>. Acesso em: 10 jan. 2014.

MARTINS, Rosane F. de F.; MERINO, Eugenio A. D. A Gestão de Design como Estratégia Organizacional. 2 ed. Londrina: Eduel; Rio de Janeiro: Rio Books, 2011. 248 p. ISBN 978-85-7216591-7 (Eduel); ISBN 978-85-61556-11-2 (Rio Books).

MOZOTA, Brigitte B. de; KLÖPSCH, Cássia; COSTA, Felipe C. X. da. Gestão do Design: Usando o Design para Construir Valor de Marca e Inovação Corporativa. Tradução: Lene Belon Ribeiro. Porto Alegre; Bookman, 2011. 343 p. ISBN: 978-85-7780-782-6.

PRETO, Seila C. S.; MARTINS, Rosane F. de F. A Gestão de Design Dirigida ao Planejamento e Comunicação dos Empreendimentos Econômicos Solidários. Rumos da Pesquisa no Design Contemporâneo: Materialidade, Gestão e Serviços (e-book). São Paulo: Estação das Letras e Cores, 2013, p. 00-00. ISBN 978-85-60166-81-7.

VALTONEN, Anna. Redefining Industrial Design: Changes in the Design Practice in Finland. Helsinki, Finland: University of Art and Design Helsinki, 2007. ISBN 978-951-558-220-1. 